\title{
Papel da luminosidade do biotério no comportamento do rato no labirinto em cruz elevado
}

\author{
Raquel Martinez \\ Andrea Milena Becerra Garcia \\ Silvio Morato \\ Universidade de São Paulo - Ribeirão Preto
}

\begin{abstract}
Resumo
Há pouca informação sobre o efeito dos ambientes onde os ratos são mantidos antes de testes. Para investigar o efeito da iluminação do biotério, ratos Wistar machos foram submetidos a um período de 96 h de iluminação contínua, escuridão contínua ou um ciclo claro escuro de 12:12 h e testados no labirinto em cruz elevado em uma sala iluminada (150 lux) ou escura (0 lux). Os resultados mostram que nem a iluminação contínua nem a escuridão contínua do biotério afetam o comportamento dos ratos, quando comparados aos sujeitos mantidos no ciclo claro-escuro de 12 h. A condição de luminosidade durante o teste, no entanto, foi importante: independentemente da condição de iluminação do biotério, os animais testados no escuro exploraram mais os braços abertos do labirinto, um resultado já relatado na literatura e interpretado como diminuição da ansiedade nesse aparato.
\end{abstract}

Palavras-chave: labirinto em cruz elevado; comportamento exploratório de ratos; iluminação do biotério; luminosidade durante o teste

\begin{abstract}
Role of vivarium illumination in rat behavior in the elevated plus-maze. There is little information about the environments where rats are kept before being tested. In order to investigate the role of vivarium illumination, male Wistar rats were submitted to a 96-h period of continuous illumination, continuous dark or a 12:12 h light/dark cycle and tested in the elevated plus-maze in a lit (150 lux) or a dark room (0 lux). Results showed that neither vivarium illumination nor darkness for $96 \mathrm{~h}$ altered the rats' behavior in comparison to that of rats kept under the 12-h light/dark cycle. Luminosity during the test, however, was important: no matter what the vivarium illumination was, rats tested in the dark room explored more the open arms of the maze, an already reported result which is interpreted as decreased anxiety in this apparatus.
\end{abstract}

Keywords: elevated plus-maze; rat exploratory behavior; vivarium illumination; luminosity during the test

$\mathrm{O}$ labirinto em cruz elevado é uma modificação de um procedimento introduzido há quase cinco décadas por Montgomery (1955), inicialmente proposto por Handley e Mithani (1984) e que se utiliza para investigar aspectos da ansiedade (e.g., Cruz, Frei, \& Graeff, 1994; Dorow, Horowski, Pashelke, Amin, \& Braestrup, 1983; Moser, 1989; Pellow \& File, 1986; Rodgers \& Cole, 1994). O método é considerado um instrumento útil e válido para medir ansiedade, investigando aspectos comportamentais, fisiológicos e farmacológicos (Anseloni \& Brandão, 1997; Cruz et al., 1994; Pellow, Chopin, File, \& Briley, 1985; Rodgers \& Cole, 1994). O teste consiste em colocar o animal em um labirinto elevado do solo formado por dois braços fechados por paredes e dois abertos, analisando-se a freqüência de entradas e o tempo gasto em cada tipo de braço, e outros comportamentos como deslocamento, levantar-se, esticarse, etc. O rato explora os dois tipos de braço, mas entra mais e permanece mais tempo nos braços fechados. Considerase a porcentagem da preferência (entradas e tempo gasto) pelos braços abertos e pelos fechados um índice fidedigno de ansiedade: quanto maiores os níveis de ansiedade, menor a porcentagem de entradas nos braços abertos e de tempo gasto nos mesmos (Handley \& Mithani, 1984; Pellow \& File, 1986).

Apesar da aparente simplicidade da situação de teste, muitos fatores influenciam a aversão aos braços abertos (para uma revisão, ver Hogg, 1996). Alguns deles são inerentes ao sujeito, como sexo (Imhof, Coelho, Schmitt, Morato, \& Carobrez, 1993; Johnston \& File, 1991) e idade (Imhof et al., 1993). Outros estão ligados ao procedimento 
experimental, como uma única ou múltiplas exposições ao labirinto (File, 1992; Griebel, Moreau, Jenck, Martin, \& Misslin, 1993; Treit, Menard, \& Royan, 1993) e a hora do dia em que o teste é feito (Gentsch, Lichtsteiner, Kraeuchi, \& Feer, 1982; Griebel et al., 1993). Além disso, características da própria situação de teste também exercem influência, como por exemplo, os níveis de luminosidade da sala experimental: há um aumento da exploração dos braços abertos quando os animais são testados com baixos níveis de luminosidade ambiental (Cardenas, Lamprea, \& Morato, 2001; Gentsch et al., 1982; Griebel et al., 1993; Morato \& Castrechini, 1989). Além disso, Garcia, Cardenas \& Morato (2005) mostraram que o aumento da exploração dos braços abertos, só acontece no teste com nível de iluminação menor que 1 lux. Acima de 3 lux e até 300 lux, essa exploração não é alterada, o que significa que existe um ponto entre 1 e 3 lux no qual acontece o aumento da exploração dos braços abertos do labirinto.

Adicionalmente, manipulações experimentais também alteram o comportamento dos animais no teste do labirinto, tais como o tipo de transporte à sala de teste (Morato \& Brandão, 1996), o alojamento individual ou em grupo (Maisonnette, Morato, \& Brandão, 1993), e o tempo de permanência no biotério antes do teste (Morato \& Brandão, 1997). Apesar de ser um modelo muito utilizado nos testes animais de ansiedade, pouco se conhece sobre o(s) evento(s) responsáveis pela aversão e quais seriam as causas da esquiva dos braços abertos. Demonstrou-se que a aversão natural dos roedores aos espaços abertos pode estar ligada à tigmotaxia (Treit et al., 1993) e não ao medo de altura, como previamente suposto (Pellow \& File, 1986). Cardenas et al. (2001) cortaram bilateralmente as vibrissas em diferentes tamanhos a partir do folículo, interferindo com a tigmotaxia normal. Os resultados mostraram que o sistema ligado às vibrissas não é a principal modalidade sensorial responsável pela exploração do labirinto em cruz elevado.

Ao contrário, Schiffman, Lore, Passafiume e Neeb (1970) sugeriram que, quando possível, os ratos utilizam a visão como principal sistema perceptivo para obter informações relevantes sobre o meio ambiente. King e Jones (2001) relataram ainda que, quando ratos eram testados no labirinto em uma condição escura, observava-se um aumento na atividade locomotora e uma diminuição da esquiva dos braços abertos. No entanto, Becker e Grecksch (1996) utilizaram três níveis de luminosidade na sala de teste do labirinto (30, 300 e 900 lux) e concluíram que o comportamento exploratório dos animais não se altera em função dos níveis de luminosidade. Contrariamente, nosso laboratório (Morato \& Castrechini, 1989) testou animais com níveis baixos de luminosidade (20 lux) e encontrou um aumento da porcentagem de entradas e do tempo gasto nos braços abertos, quando comparados com os animais testados com altos níveis de luminosidade (1200 lux). Apoiando os nossos resultados, Griebel et al. (1993) relataram que altos níveis de luminosidade diminuem significativamente a atividade to- tal, a porcentagem de entradas e a porcentagem de tempo gasto nos braços abertos, em comparação com os baixos níveis de luminosidade, e concluíram que a luminosidade altera o comportamento exploratório dos ratos no labirinto em cruz elevado.

Nasello, Machado, Bastos e Felicio (1998) estudaram os efeitos da escuridão súbita sobre o comportamento exploratório no labirinto e demonstraram que os animais exibiam um aumento na freqüiência e porcentagem de entradas e tempo gasto nos braços abertos, assim como no total de entradas. Esse mesmo aumento na atividade locomotora foi observado quando se testavam os animais no campo aberto na ausência de luminosidade ou em situação de escuridão repentina (Nasello et al., 1998; Valle, 1970).

Martinez, Cardenas, Lamprea e Morato (2002) investigaram o papel da presença de bordas transparentes circundando os braços abertos com diferentes alturas: 1, 5, 10,20 e $40 \mathrm{~cm}$. Adicionalmente, a parede transparente de $40 \mathrm{~cm}$ foi também recoberta com papel branco translúcido ou preto opaco. Os animais evitaram os braços abertos circundados por paredes transparentes de 1 e $40 \mathrm{~cm}$ (as últimas permitiam tigmotaxia, tinham a mesma altura das paredes de madeira dos braços fechados e permitiam a visão desimpedida). Além disso, quando as paredes transparentes de $40 \mathrm{~cm}$ foram cobertas com os papéis branco ou preto houve um aumento no comportamento exploratório nesses braços, sendo que foi maior com o papel preto e menor com o branco, indicando que a visão pode ser a responsável pela aversão e pela diminuição da exploração aos mesmos.

Com base nas sugestões de que a visão é uma importante modalidade sensorial no comportamento exploratório e no desencadear da ansiedade, o objetivo do presente estudo foi investigar os efeitos de diferentes condições de iluminação ambiental tanto durante o período de manutenção que antecede o teste no labirinto em cruz elevado como durante o teste.

\section{Material e Métodos}

\section{Sujeitos}

Utilizaram-se 72 ratos machos de uma derivação Wistar, pesando $200 \pm 10 \mathrm{~g}$, provenientes do biotério central da Universidade de São Paulo, em Ribeirão Preto. Todos os sujeitos foram submetidos a um período de habituação de 3 dias antes de iniciar o experimento. Os sujeitos foram alojados em grupos de seis por caixa de polipropileno (40 x $34 \mathrm{x}$ $17 \mathrm{~cm}$ ). Após o período de habituação, os ratos foram aleatoriamente distribuídos em três grupos conforme a condição de iluminação ambiental. Um grupo (Luz, L) foi submetido a 96 horas de iluminação constante, outro (Escuro, E) a 96 horas de escuridão constante, e um terceiro (Controle, C) foi mantido em ciclo claro-escuro de 12:12 h (luzes acesas às 7:00 h). Um dispositivo termostático manteve a temperatura 
do biotério entre 24 e $27^{\circ} \mathrm{C}$. Todos os sujeitos tiveram livre acesso à água e comida. O teste comportamental realizou-se entre 8:00 e 11:30 h. Os procedimentos relatados neste artigo estão de acordo com as recomendações feitas pela Sociedade Brasileira de Neurociências e Comportamento (Brazilian Society of Neuroscience and Behavior), baseadas no US National Institutes of Health Guide for Care and Use of Laboratory Animals.

\section{Equipamento}

Utilizou-se um labirinto em cruz elevado, descrito detalhadamente alhures (Lamprea, Cardenas, Silveira, Morato, \& Walsh, 2000). O aparato consiste de duas superfícies horizontais de madeira com piso de fórmica, medindo 50x10 cm, justapostas pelas pontas, com bordas de acrílico de $1 \mathrm{~cm}$ de altura (braços abertos), cruzados em angulo reto com duas superfícies de igual tamanho, circundadas por paredes de $40 \mathrm{~cm}$ de altura (braços fechados) exceto na parte central onde os braços se cruzam. Todo o aparato eleva-se a $50 \mathrm{~cm}$ do piso. A lâmpada se encontrava $1,5 \mathrm{~m}$ acima do aparato. Circundando os braços abertos havia uma borda de acrílico de $1 \mathrm{~cm}$ de altura com a finalidade de evitar que os ratos caíssem. As sessões experimentais foram gravadas por uma câmera de vídeo com luz infravermelha que permitia gravar no escuro e que se encontrava na sala adjacente ligada a um monitor e a um aparelho de vídeo cassete. Para o registro do deslocamento e outros comportamentos do animal, sobre a tela da televisão, colocou-se uma transparência na qual se podia dividir a imagem do piso do labirinto em quadrados de 10 cm. Posteriormente, registrou-se o número de quadrados atravessados pelo animal e o local exato onde ocorreram os comportamentos gravados.

\section{Procedimento}

Após 96 h em uma das três condições de manutenção, todos os sujeitos foram testados no labirinto em cruz elevado. Dividiu-se cada grupo em dois sub-grupos, um testado na condição de luz (150 lux no quadrado central do labirinto) e o outro em total escuridão (0 lux). Desse procedimento resultaram seis grupos: C150, C0, L150, L0, E150 e E0. A primeira letra indica a condição de luminosidade no biotério, descrita na seção Sujeitos e o número representa o nível de luminosidade na sala de teste. Para o teste comportamental, colocou-se gentilmente cada animal na área central do labirinto com o focinho voltado para um dos braços fechados e se permitiu a livre exploração por 5 minutos. Depois de testar cada animal o aparato era limpo com uma solução de etanol de $20 \%$. Registraram-se as medidas convencionais (número de entradas e tempo gasto nos braços), assim como a freqüência e o tempo gasto nas categorias comportamentais descritas a seguir. (a) Mergulhar a cabeça: dirigir a cabeça abaixo do nível do piso do labirinto. (b) Esticar-se: mover lentamente as patas dianteiras mantendo imóveis a traseiras, causando um alongamento do corpo, e voltando as dianteiras à sua posição inicial. (c) Levantar-se: erguer-se total ou parcialmente apoiando-se nas patas traseiras, com as dianteiras tocando ou não as paredes. (d) Limpar-se: seqüência de comportamentos de auto-limpeza específicos da espécie, incluindo passar a língua ou as patas em partes do corpo (Cruz et al., 1994). Registraram-se também o número de entradas e o tempo gasto nas extremidades (20 cm distais) dos braços abertos e fechados bem como a distância percorrida nos braços (estimada a partir do número de quadrados atravessados).

\section{Análises estatísticas}

Os dados foram submetidos a uma análise de variância de duas vias (ANOVA), tendo como um dos fatores o nível de iluminação do biotério (três níveis: C, L, E) e como o outro fator a condição de luminosidade da sala de teste (dois níveis: 0 e 150 lux). Sempre que apropriado, utilizou-se o teste de comparações múltiplas entre médias de grupos de Newman-Keuls. Para todos os testes, utilizou-se $p<0,05$ como nível de significância.

\section{Resultados}

A Figura 1 apresenta a porcentagem de entradas e tempo nos braços abertos, assim como a freqüência e o tempo gasto nas extremidades dos mesmos. Com relação à porcentagem de entradas nos braços abertos, a ANOVA mostrou um efeito geral devido ao fator luminosidade durante o teste $(F(2,66)=67,33 ; p<0,001)$, mas não ao fator iluminação do biotério $(F(1,660)=1,40 ; p=0,26)$; tampouco houve interação entre os fatores $(F(2,66)=1,65 ; p=0,20)$. O teste de comparações múltiplas mostrou um aumento na porcentagem de entradas dos animais testados na sala escura (C0, L0 e E0) em comparação com os animais testados na condição de luz (C150, L150 e E150). Quanto ao tempo gasto nos braços abertos, a ANOVA não mostrou efeitos gerais devidos à iluminação do biotério $(F(2,66)=2,33 ; p=0,11)$, mas devidos à luminosidade durante o teste $(F(1,660)=83,67 ; p<0,001)$. Não ocorreu interação entre os fatores $(F(2,66)=0,86$; $p=0,43)$. $\mathrm{O}$ teste Newman-Keuls mostrou que todos os animais testados no escuro (C0, L0 e E0) gastaram mais tempo nos braços abertos em comparação com os testados no claro (C150, L150 e E150).

Com relação ao número de entradas nas extremidades dos braços abertos, a ANOVA revelou efeitos gerais devidos ao fator iluminação do biotério $(F(2,66)=19,92 ; p<0,001)$, e à luminosidade durante o teste $(F(1,660)=10,67 ; p=0,001)$, além uma interação entre os fatores $(F(2,66)=4,57 ; p=0,01)$. O teste post hoc mostrou que os animais dos grupos testados na sala escura (C0, L0, E0) entraram significativamente mais nas extremidades do que os testados no claro (C150, L150, E150). Finalmente no tempo gasto nas extremidades abertas, a ANOVA acusou efeitos gerais devidos ao fator iluminação do biotério $(F(2,66)=23,81 ; p<0,001)$ e ao fator 


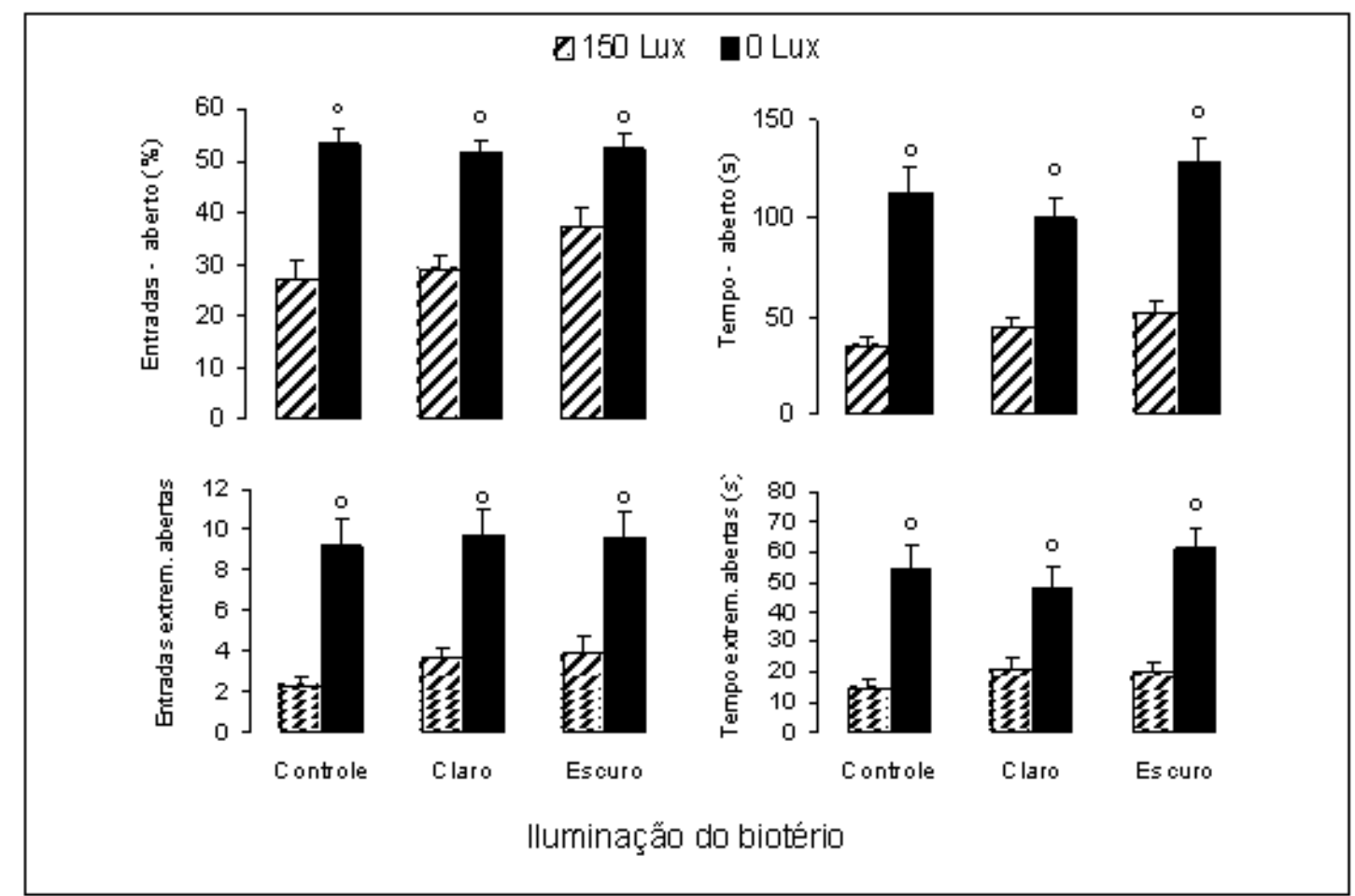

Figura 1. Porcentagem de entradas e tempo gasto (acima) nos braços abertos e entradas e tempo gasto nas extremidades dos mesmos (abaixo) mostradas pelos ratos mantidos sob iluminação ou escuridão constantes ou em ciclo claro/escuro de 12:12 h e testados sob duas condições de luminosidade (0 e 150 lux). As barras representam as médias e as linhas verticais indicam o EPM. O símbolo ${ }^{\circ}$ indica que o valor foi significativamente diferente do grupo alojado no biotério sob o mesmo nível de iluminação, porém testado com luminosidade (Newman-Keuls; $p<0,05$ ).

luminosidade durante o teste $(F(1,66)=7,53 ; p=0,01)$; não houve interação entre os fatores $(F(2,66)=2,13$; $p=0,13)$. $\mathrm{O}$ teste de Newman-Keuls mostrou um aumento no tempo gasto nas extremidades dos braços abertos pelos animais dos grupos testados no escuro (C0, L0, E0) em comparação com os animais testados no claro (C150, L150, E150).

A Figura 2 apresenta o número de entradas nos braços fechados. A ANOVA revelou um efeito geral devido ao fator iluminação do biotério $(F(2,66)=7,27 ; p=0,01)$, mas não à luminosidade durante o teste $(F(1,660)=1,94 ; p=0,17)$; não houve interação entre os fatores $(F(2,66)=0,61 ; p=0,54)$. O teste post hoc revelou que o grupo L150 entrou mais vezes nos braços fechados do que o grupo controle (C150). A Figura 2 também apresenta a distância percorrida pelos animais nos braços fechados. A ANOVA mostrou um efeito geral devido ao fator iluminação do biotério $(F(2,66)=3,92 ; p=0,02)$, mas não à luminosidade durante 0 teste $(F(1,66)=0,67 ; p=0,42)$; não houve interação entre os fatores $(F(2,66)=0,29 ; p=0,75)$. Apesar da indicação de efeitos da iluminação do biotério pela ANOVA, o teste post hoc não acusou quaisquer diferenças entre os grupos. No teste ANOVA foram comparados os diferentes níveis de uma mesma variável (ex. claro vs escuro), enquanto que no teste post hoc as comparações são feitas entre pares de grupos, razão pela qual possivelmente não foram encontradas as diferenças.

A Tabela 1 mostra as médias ( \pm EPM) dos comportamentos exibidos pelos animais no labirinto em cruz elevado e a Tabela 2 apresenta os resultados das análises estatísticas aplicadas a esses parâmetros. A ANOVA mostrou efeitos gerais devidos ao fator iluminação do biotério na freqüência de levantar-se, (o grupo E0 aumentou a freqüência de levantar quando comparado com o grupo $\mathrm{C} 0$ ), na freqüência de limpar-se (o grupo E150 diminuiu comparado com o C150) e no tempo gasto limpando-se (o grupo L150 diminuiu comparado ao C150). A ANOVA também mostrou efeitos gerais devidos à luminosidade durante o teste, os grupos testados em 0 lux exibiram um aumento nos parâmetros de entradas nos braços abertos, freqüência e o tempo esticando-se e mergulhando a cabeça, bem como na freqüência de levantar-se quando comparados com os testados em 150 lux. 


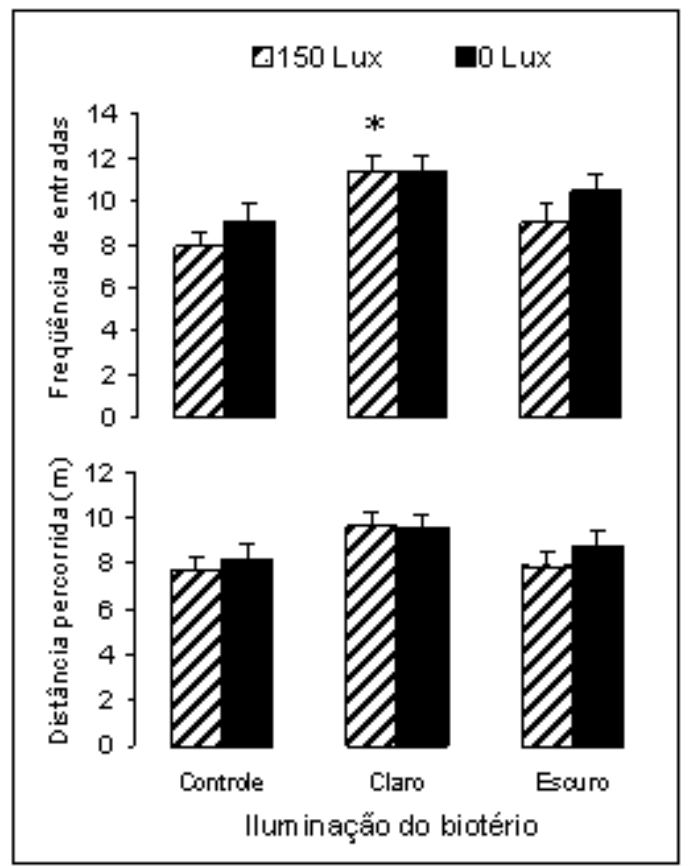

Figura 2. Freqüência de entradas (acima) e distância percorrida (abaixo) nos braços fechados pelos ratos mantidos sob iluminação ou escuridão constantes ou em ciclos claro/escuro de 12:12 h e testados sob duas condições de luminosidade (0 e 150 lux). As barras representam as médias e as linhas verticais indicam o EPM. O símbolo * indica que o valor foi significativamente diferente do grupo controle testado com o mesmo nível de iluminação durante o teste (Newman-Keuls; $p<0,05)$.

\section{Discussão}

Independentemente da condição de iluminação do biotério, observa-se um aumento na porcentagem de entradas e no tempo gasto nos braços abertos quando os animais são testados no escuro, em comparação com os animais testados no claro. O mesmo tipo de efeito foi observado quanto à exploração das extremidades abertas. Isso mostra que os efeitos observados deveram-se ao nível de luminosidade durante o teste, apoiando a hipótese amplamente relatada na literatura de que o nível de iluminação da área experimental é um determinante crítico do comportamento no labirinto em cruz elevado (Griebel et al., 1993). A literatura relata um aumento da esquiva aos braços abertos quando a sala do teste é muito iluminada (Griebel et al., 1993; Jerome, Moody, Connor, \& Fernandez, 1957; Morato \& Castrechini, 1989). Essa esquiva é confirmada no nosso trabalho e evidencia-se pela diminuição na porcentagem de entradas e tempo gasto nos braços abertos e em suas extremidades (Pellow et al., 1985; Setem, Pinheiro, Motta, Morato, \& Cruz, 1999). Na literatura, es- sas medidas são inversamente associadas aos níveis de ansiedade (Cruz et al., 1994; Setem et al., 1999), sugerindo que a diminuição no nível de luminosidade da sala de teste exerce um efeito ansiolítico sobre o comportamento exibido no labirinto em cruz elevado.

A redução no comportamento de esticar-se aqui descrita já foi relatada na literatura após a injeção de drogas ansiolíticas (Cole \& Rodgers, 1993) bem como seu aumento devido à injeção de drogas ansiogênicas (Anseloni \& Brandão, 1997), sugerindo que o escuro durante o teste é o principal causador do efeito ansiolítico. Na mesma linha de raciocínio, a ausência de luz também fez aumentar a freqüência e duração do comportamento de mergulhar a cabeça, inversamente associado à ansiedade (Anseloni \& Brandão, 1997; Cole \& Rodgers, 1993). A ausência de luz durante o teste alterou apenas os comportamentos ligados à ansiedade, evidenciado pelo fato de que as medidas de atividade geral não se modificaram. Apenas um grupo apresentou aumento na freqüência de entradas nos braços fechados mas não na distância percorrida nem no comportamento de levantar-se, sugerindo talvez que esse aumento seja um efeito isolado.

Com relação à influência do ciclo claro/escuro sobre o comportamento no labirinto em cruz elevado, Bertoglio e Carobrez (2002) testaram animais nas fases diurna e noturna do ciclo, e observaram uma redução na porcentagem de entradas e no tempo gasto nos braços abertos, quando os animais foram testados na fase noturna. Por outro lado, quando o teste acontece em condições de baixa luminosidade essas medidas aumentam independentemente da fase do ciclo.

Nossos resultados mostraram que forçar os animais a permanecerem por $96 \mathrm{~h}$ em escuridão ou iluminação constantes não altera as medidas convencionais de ansiedade nem as de atividade exploratória no labirinto em cruz elevado. No entanto, o nível de luminosidade durante o teste foi crucial para definir o comportamento exploratório dos ratos. Isso sugere que, durante a exploração de um ambiente novo a visão pode ser a principal modalidade sensorial utilizada pelos ratos, conforme já sugerido por Schiffman et al. (1970) de modo geral e por nosso laboratório (Martinez et al., 2002), no caso mais específico do labirinto em cruz elevado.

Pode-se concluir, portanto, que a luminosidade durante o teste foi a responsável pelas diferenças observadas no comportamento exibido no labirinto em cruz elevado, e que a condição iluminação do biotério não alterou o padrão comportamental dos animais. Uma possível explicação é que a visão pode ser usada como principal sistema perceptivo para a obtenção de informação relevante e para causar a aversão natural aos espaços abertos somente na situação de teste, a qual pode ser reduzida quando os animais são testados no escuro. A principal contribuição do presente trabalho, é a demonstração de que a permanência forçada numa determinada condição de iluminação no biotério estaria, assim, desvinculada da situação de teste. 
Tabela 1

Freqüência e tempo gasto nos comportamentos exibidos no labirinto em cruz elevado

\begin{tabular}{|c|c|c|c|c|c|c|}
\hline \multirow[t]{3}{*}{ Parâmetros } & \multicolumn{2}{|c|}{ Controle } & \multicolumn{2}{|c|}{ Claro } & \multicolumn{2}{|c|}{ Escuro } \\
\hline & 150 lux & 0 lux & $150 \operatorname{lux}$ & 0 lux & $150 \operatorname{lux}$ & 0 lux \\
\hline & Média EPM & Média EPM & Média EPM & Média EPM & Média EPM & Média EPM \\
\hline Entradas nos braços abertos & $3,3 \pm 0,6$ & $10,8 \pm 1,1$ & $4,9 \pm 0,6$ & $12,2 \pm 0,9$ & $5,3 \pm 0,7$ & $12,1 \pm 1,3$ \\
\hline Tempo gasto no quadrado central (s) & $40,1 \pm 5,3$ & $45,3 \pm 4,5$ & $57,4 \pm 4,7$ & $48,7 \pm 4,6$ & $38,5 \pm 5,0$ & $50,2 \pm 4,2$ \\
\hline Freqüência de esticar & $5,8 \pm 0,9$ & $1,3 \pm 0,5$ & $5,8 \pm 1,2$ & $1,4 \pm 0,5$ & $4,1 \pm 0,9$ & $1,8 \pm 0,9$ \\
\hline Tempo gasto esticando-se (s) & $3,9 \pm 0,7$ & $1,2 \pm 0,6$ & $3,8 \pm 0,7$ & $0,6 \pm 0,2$ & $3,1 \pm 0,7$ & $1,2 \pm 0,7$ \\
\hline Freqüência de levantar-se & $17,6 \pm 1,4$ & $20,8 \pm 2,1$ & $20,8 \pm 1,5$ & $23,8 \pm 1,9$ & $20,6 \pm 1,5$ & $27,8 \pm 2,1$ \\
\hline Tempo gasto levantando-se (s) & $23,8 \pm 2,4$ & $29,8 \pm 3,0$ & $29,9 \pm 2,8$ & $28,8 \pm 1,9$ & $27,3 \pm 2,7$ & $34,9 \pm 3,4$ \\
\hline Freqüência de autolimpeza & $9,1 \pm 1,5$ & $6,8 \pm 1,2$ & $7,9 \pm 1,0$ & $5,2 \pm 0,6$ & $4,5 \pm 0,9$ & $4,7 \pm 0,4$ \\
\hline Tempo gasto limpando-se (s) & $34,5 \pm 6,4$ & $15,9 \pm 4,9$ & $14,0 \pm 2,8$ & $18,8 \pm 3,8$ & $23,7 \pm 5,9$ & $14,7 \pm 2,9$ \\
\hline Freqüência de mergulhar a cabeça & $11,5 \pm 1,2$ & $26,2 \pm 2,6$ & $12,5 \pm 1,1$ & $30,7 \pm 2,6$ & $18,4 \pm 2,3$ & $30,0 \pm 2,6$ \\
\hline Tempo gasto mergulhando a cabeça (s) & $11,3 \pm 1,1$ & $34,7 \pm 5,0$ & $14,4 \pm 2,3$ & $29,5 \pm 3,6$ & $21,4 \pm 2,9$ & $41,8 \pm 3,4$ \\
\hline
\end{tabular}

Tabela 2

Resultados estatísticos da ANOVA de duas vias aplicada aos parâmetros estudados

\begin{tabular}{|c|c|c|c|c|c|c|c|c|}
\hline \multirow[t]{2}{*}{ Parâmetros } & \multicolumn{2}{|c|}{ Biotério } & \multicolumn{2}{|c|}{ Teste } & \multicolumn{2}{|c|}{ Interação } & \multicolumn{2}{|c|}{ Diferente de } \\
\hline & $F(2,66)$ & $p$ & $F(1,66)$ & $p$ & $F(2,66)$ & $p$ & controle & 150 lux \\
\hline Entradas nos braços abertos & 1,989 & 0,145 & 90,220 & $<0,001^{*}$ & 0,071 & 0,932 & & C, L, E \\
\hline Tempo gasto no quadrado central (s) & 2,766 & 0,070 & 0,524 & 0,472 & 2,441 & 0,095 & & \\
\hline Freqüência de esticar & 0,312 & 0,733 & 27,753 & $<0,001^{*}$ & 1,065 & 0,350 & & C, L \\
\hline Tempo gasto esticando-se (s) & 0,259 & 0,773 & 24,654 & $<0,001^{*}$ & 0,505 & 0,606 & & C, L, E \\
\hline Freqüência de levantar-se & 4,060 & $0,020 *$ & 9,520 & $0,002^{*}$ & 0,880 & 0,410 & E0 & E \\
\hline Tempo gasto levantando-se (s) & 1,204 & 0,307 & 3,662 & 0,060 & 1,460 & 0,240 & & \\
\hline Freqüência de autolimpeza & 5,533 & $0,006^{*}$ & 3,972 & 0,050 & 1,227 & 0,300 & E150 & \\
\hline Tempo gasto limpando-se (s) & 1,855 & 0,164 & 3,814 & 0,055 & 3,121 & 0,051 & L 150 & $\mathrm{C}$ \\
\hline Freqüência de mergulhar a cabeça & 2,991 & 0,057 & 70,258 & $<0,001^{*}$ & 1,429 & 0,247 & & C, L, E \\
\hline Tempo gasto mergulhando a cabeça (s) & 5,273 & $0,008^{*}$ & 53,259 & $<0,001^{*}$ & 0,825 & 0,443 & & C, L, E \\
\hline
\end{tabular}

Nota: as duas colunas da direita indicam diferenças em comparação com o respectivo controle (Grupo Co) e com o grupo testado na condição clara (150 lux)

* $p<0,05$

\section{Referências}

Anseloni, V. Z., \& Brandão, M.L. (1997). Ethopharmacological analysis of behavior of rats using variations of the elevated plus-maze. Behavioural Pharmacology, 8, 533-540.

Becker, A., \& Grecksch, G. (1996). Illumination has no effect on rats' behavior in the elevated plus-maze. Physiology \& Behavior, 59, 175-177.

Bertoglio L. J., Carobrez A. P. (2002) Behavioral profile of rats submitted to session 1-session 2 in the elevated plus-maze during diurnal/nocturnal phases and under different illumination conditions. Behavioral Brain Research, 132, 135-143.

Cardenas, F., Lamprea, M. R., \& Morato, S. (2001). Vibrissal sense is not the main sensory modality in the rat exploratory behavior in the elevated plusmaze. Behavioural Brain Research, 122, 169-174.

Cole, J. C., \& Rodgers, R. J. (1993). An ethological analysis of the effects of chlordiazepoxide and bretazenil (Ro 16-6028) in the murine elevated plusmaze. Behavioural Pharmacolgy, 4, 573-580.
Cruz, A. P. M., Frei, F., \& Graeff, F. G. (1994). Ethopharmacological analysis of rat behavior on the elevated plus-maze. Pharmacology Biochemistry and Behavior, 49, 171-176.

Dorow, R., Horowski, R., Pashelke, G., Amin, M., \& Braestrup, C. (1983). Severe anxiety induced by FG7142, a -carboline for benzodiazepine receptors. Lancet, 9, 98-99.

File, S. E. (1992). Behavioural detection of anxiolytic action. In J. M. Elliott, D. J. Heal, \& C. A. Marsden (Orgs.), Experimental approaches to anxiety and depression (pp. 25-44). Nova York: Wiley.

Garcia, A. M. B., Cardenas F. P., \& Morato S. (2005). Effect of different illumination levels on rat behavior in the elevated plus-maze. Physiology \& Behavior, 85, 265-270.

Gentsch, C., Lichtsteiner, M., Kraeuchi, K., \& Feer, H. (1982). Different reaction patterns in individually and socially reared rats during exposures to novel environments. Behavioural Brain Research, 4, 45-54. 
Griebel, G., Moreau, J-L., Jenck, F., Martin, J. R., \& Misslin, R. (1993). Some critical determinants of the behaviour of rats in the elevated plus-maze. Behavioural Processes, 29, 37-48.

Handley, S. L., \& Mithani, S. (1984). Effects of alpha-adrenoceptor agonists and antagonists in a maze-exploration model of 'fear'- motivated behaviour. Naunyn-Schmiedeberg's Archives of Pharmacology, 327, 1-5.

Hogg, S. (1996). A review of the validity and variability of the elevated plus-maze as an animal model of anxiety. Pharmacology Biochemistry and Behavior, 54, 21-30.

Imhof, J. T., Coelho, Z. M. I., Schmitt, M. L., Morato, G. S., \& Carobrez, A. P. (1993). Influence of gender and age on performance of rats in the elevated plus-maze apparatus. Behavioral Brain Research, 56, 177-180.

Jerome, E., Moody, J. A., Connor, T. J., \& Fernandez, M. B. (1957). Learning in a multiple-door situation under various drive states. Journal of Comparative Psychology, 50, 588-591.

Johnston, A. L., \& File, S. E. (1991). Sex differences in animal tests of anxiety. Physiology and Behavior, 49, 245-250.

King, S. M., \& Jones, N. (2001). Influence of circadian phase and test illumination on pre-clinical models of anxiety. Physiology \& Behavior, 72, 99-106.

Lamprea, M. R., Cardenas, F. P., Silveira, R., Morato, S., \& Walsh, T. J. (2000). Dissociation of memory and anxiety in a repeated elevated plus-maze paradigm: forebrain cholinergic mechanisms. Behavioral Brain Research, 117, 97-105.

Maisonnette, S., Morato, S., \& Brandão, M. L. (1993). Role of resocialization and of 5-HT1A receptor activation on the anxiogenic effects induced by isolation in the elevated plus-maze test. Physiology and Behavior, 54, 753758.

Martinez, J. C., Cardenas, F., Lamprea, M., \& Morato, S. (2002). The role of vision and proprioception in the aversion of rats to the open arms of an elevated plus maze. Behavioral Processes, 60, 15-26.

Montgomery, K. C. (1955). The relation between fear induced by novel stimulation and exploratory behavior. Journal of Comparative Physiology and Psychology, $48,254-260$.
Morato, S., \& Brandão, M. L. (1996). Transporting rats to the test situation on a cart can modify rat exploratory behavior in the elevated plus-maze. Psychobiology, 24, 247-252.

Morato, S., \& Brandão, M. L. (1997). Paradoxical increase of exploratory behavior in the elevated plus-maze by rats exposed a two kinds of aversive stimuli. Brazilian Journal of Medical and Biological Research, 30, 1113-1120.

Morato, S., \& Castrechini, P. (1989). Effects of floor and environmental illumination on exploratory activity in the elevated plus-maze. Brazilian Journal of Medical and Biological Research, 22, 707-710.

Moser, P. C. (1989). An evaluation of the elevated plus maze test using the novel anxiolytic buspirone. Psychopharmacology, 99, 48-53.

Nasello, A. G., Machado, C., Bastos, J. F., \& Felicio, L. F. (1998). Sudden darkness induces a high activity-low anxiety state in male and female rats. Physiology \& Behavior, 63, 451-454.

Pellow, S., \& File, S. E. (1986). Anxiolytic and anxiogenic drug effects on exploratory activity in elevated plus-maze: a novel test of anxiety in the rat. Pharmacology, Biochemistry and Behavior, 24, 525-529.

Pellow, S., Chopin, P., File, S. E., \& Briley, M. (1985). Validation of openclosed arm entries in an elevated plus-maze as a measure of anxiety in the rat. Journal of Neuroscience Methods, 14, 149-167.

Rodgers, R. J., \& Cole, J. C. (1994). The elevated plus-maze: Pharmacology, methodology and ethology. In S. J. Cooper \& C. A. Hendrie (Orgs.), Ethology and Psychopharmacology (pp. 9-43). Nova York: Wiley.

Schiffman, H. R., Lore, R., Passafiume, J., \& Neeb, R. (1970). Role of vibrissae for depth perception in the rat (Rattus novergicus). Animal Behavior, 18, 290-292.

Setem, J., Pinheiro, A. P., Motta, V. A., Morato, S., \& Cruz, A. P. M. (1999) Ethopharmacological analysis of 5-HT ligands on the rat elevated plusmaze. Pharmacology Biochemistry and Behavior, 62, 515-521.

Treit, D., Menard, J., \& Royan, C. (1993). Anxiogenic stimuli in the elevated plus-maze. Pharmacology Biochemistry and Behavior, 44, 463-469.

Valle, F. P. (1970). Effects of strain, sex, and illumination on open-field behavior of rats. American Journal of Psychology, 83, 103-111.

Raquel Chacon Ruiz Martinez é mestre e doutoranda em Psicobiologia pela Universidade de São Paulo, Ribeirão Preto. E-mail: quelmartinez@hotmail.com

Andrea Milena Becerra Garcia é mestre e doutoranda em Psicobiologia pela Universidade de São Paulo, Ribeirão Preto. E-mail: angarcia@usp.br

Silvio Morato, doutor em Farmacologia pela Faculdade de Medicina de Ribeirão Preto-USP, é professor associado no Departamento de Psicologia e Educação, Faculdade de Filosofia Ciências e Letras, Universidade de São Paulo, Ribeirão Preto. Endereço para correspondência: Faculdade de Filosofia, Ciências e Letras de Ribeirão Preto; Av. Bandeirantes, 3900; Ribeirão Preto, SP; CEP 14040-901. Tel: (16) 602-3662 Fax: (16) 633-5668. E-mail: smorato@ffclrp.usp.br 



\title{
Miscigenação versus bipolaridade racial: contradições e conseqüências opressivas do discurso nacional sobre raças
}

\author{
Pedro de Oliveira Filho \\ Universidade Estadual da Paraíba
}

\begin{abstract}
Resumo
Analisamos discursos de brancos acerca do modo bipolar de classificação racial. A abordagem teóricometodológica adotada aqui enfatiza a função e os efeitos do discurso. Freqüentemente, nesses discursos, o modo bipolar é posicionado como racista e o povo brasileiro é apresentado como uma raça mestiça, como um povo sem divisões raciais. São discursos que terminam por obliterar o nosso racismo e a desigualdade entre negros e brancos no Brasil.
\end{abstract}

Palavras-chave: discurso; racismo; classificação racial; miscigenação; psicologia social

\begin{abstract}
Miscegenation against racial bipolarity: contradictions and oppressive effects of national discourse about races. This article analyzes discourses of white people about the bipolar system of racial classification. It focuses on the function and effects of discourse. Often, in these discourses, the bipolar system of racial classification appears as a product of racism and the Brazilian people appear as a mixed race, as a people free of racial separation. They are discourses that hide our racism and the inequality between whites and blacks.
\end{abstract}

Keywords: discourse; racism; racial classification; miscegenation; social psychology

$\mathrm{N}$ o modo de classificação racial dominante na sociedade norte-americana existem somente negros e brancos, não existem categorias intermediárias. Esse modo bipolar de classificação racial está baseado na regra segundo a qual um antepassado negro é suficiente para que um indivíduo seja categorizado como negro. No Brasil, por outro lado, predomina o modo multipolar (ou múltiplo) de classificação racial. Indivíduos com antepassados negros podem ser negros, mas também podem ser mulatos, morenos, pardos, de cor, brancos, etc.

Os brasileiros, em geral, vêem o predomínio do modo multipolar no Brasil como prova de nossa superioridade em relação aos norte-americanos em termos de relações raciais. Fry (1995/1996), um representante desse pensamento no meio acadêmico, argumenta que o modo bipolar norte-americano seria essencialista e mais racista que o modo multipolar.

Por outro lado, diversos autores (d’Adesky, 2001; Munanga, 1999; Skidmore, 1991) e militantes de movimentos afro-brasileiros acentuam as conseqüências políticas negativas advindas do predomínio do modo multipolar no Brasil. Para eles, uma classificação com várias ou mesmo com três categorias raciais seria um artifício ideológico para dividir os não-brancos. Nessa perspectiva, a generalização do uso do modo bipolar de classificação racial no Brasil seria fundamental para tornar mais eficiente a luta dos afro-brasileiros por igualdade social e econômica entre brancos e não-brancos.

Este trabalho, embora não parta do pressuposto de que o predomínio do modo bipolar de classificação racial (ou de qualquer outro modo de classificação racial) seja uma condição necessária para que tenhamos uma sociedade mais igualitária em termos raciais, procura evidenciar que a defesa do modo de classificação racial com múltiplas categorias raciais (categorias sem limites bem definidos) e a apologia da miscigenação que geralmente a acompanha assumem com grande freqüência um caráter ideológico e mistificador nos discursos dos brasileiros. Seu objetivo é analisar as estratégias discursivas utilizadas por brancos brasileiros no combate ao diferencialismo racial que fundamenta o modo bipolar de classificação racial, evidenciar as conseqüências opressivas decorrentes de certos usos do discurso universalista (ou antidiferencialista) associado ao modo multipolar de classificação racial, tal como funciona no Brasil, e evidenciar as contradições, ambigüidades e tensões que caracterizam tal discurso. 


\section{Método}

Utiliza-se neste trabalho a abordagem teóricometodológica de um grupo de pesquisadores da psicologia social (Billig, 1985, 1987, 1991; Potter, 1996; Potter \& Wetherell, 1987; Potter, Wetherell, Gill, \& Edwards, 1990; Wetherell, 1996; Wetherell \& Potter, 1992) que enfatizam a natureza retórica do discurso, sua função e variabilidade.

O tema em questão neste artigo faz parte de uma pesquisa mais ampla, na qual foram entrevistados 60 (sessenta) participantes, fenotipicamente brancos, de diferentes classes sociais e residentes na cidade de Campinas-SP.

Os participantes foram submetidos a um roteiro de entrevista parcialmente estruturado, contendo diversos questionamentos sobre as relações raciais no Brasil. Os discursos analisados aqui são, em sua maioria, respostas ao questionamento acerca da regra segundo a qual um antepassado negro é suficiente para que um indivíduo seja classificado como negro. Todos os participantes cujas falas são analisadas no texto aparecem com nomes fictícios.

\section{Modo bipolar e racismo diferencialista}

Nos discursos dos entrevistados, uma das estratégias mais freqüentes de combate ao modo bipolar é associá-lo, de maneira explícita ou implícita, a um diferencialismo racista de setores não-negros da população:

Lúcio: Não. Normal, porque se eu for afirmar, ah é negro! eu vou tá sendo também...eu vou ser...tá sendo um pouco...preconceituoso. Eu acho que...não tem nada disso, não. Os negros, brancos, tudo é capaz, a mesma coisa, como têm muitas pessoa negra aí no poder, branca também.

João: Não, eu... é normal, branco, negro, tanto faz... pode ser moreno ou pode ser branco. Eu, pra mim não tem a diferença, o pessoal quer colocar, né?, moreno, pode colocar o branco, tanto faz, são todos iguais. Pra mim... É o que eu tô dizendo, pra mim não há diferença nenhuma. Morena, pra mim são todos num nível só. Não tem esse negócio contra... racista. Jamais.

Maciel: Quem pensa assim é o povo que... que... o povo racista, né. Que eu não sei, eu acho... Não tem por que achar, só porque o avô é negro, achar que a pessoa, por mais clara que seja, seja... seja negra também. Sei lá, não existe, não entendo isso.

Tereza: Eu queria ter um antepassado negro (sorrindo). Mas... é... eu não acho... Eu não gosto de caracterizar, se a pessoa é branca, se a pessoa é negra, não. Eu acho assim: independente do tom de pele dela, é pessoa, entendeu?

Geraldo: Eu acho que ser negro, ter um antepassado negro... Eu não vejo essa preocupação, entendeu?, de classificar como negro, como pardo, como mestiço. Acho que não... não faz sentido, não aparenta, a pessoa é uma pessoa, é um indivíduo.
A frase quem escapa de branco é negro é bem característica do modo como esse diferencialismo se apresenta no contexto nacional entre os brancos mais incomodados com a falta de critérios mais claros de classificação racial no Brasil. É a esse racismo diferencialista (geralmente associado pelos brasileiros aos Estados Unidos), racismo que não gosta de ambigüidades nem de misturas, que os entrevistados acima combatem com recursos interpretativos tirados do nosso discurso da democracia racial.

Em algumas falas, o discurso da bipolaridade é posicionado como racista com o argumento segundo o qual tal discurso tem como pressuposto a inferioridade racial do negro. Em outras falas, o modo bipolar de classificação racial é posicionado como racista argumentando-se contra o ato classificatório em si mesmo, contra a necessidade de colocar as pessoas em categorias raciais.

Tereza e Geraldo nos sugerem que, para combater eficientemente o racismo, só precisamos aprender a ver os membros de todos os grupos sociais como indivíduos, como pessoas; só precisamos deixar de pensar no mundo social a partir de categorias como negro, branco, etc. Nesses discursos, como em alguns teóricos da cognição social (Hamilton \& Gifford, 1976; Taylor, Fiske, Etcoff, \& Ruderman, 1978), que tentam explicar a origem dos estereótipos sobre os grupos minoritários a partir de processos cognitivos, o problema parece ser a simplificação e distorção resultantes do processo de categorização através do qual organizamos o mundo social.

Esses discursos pregam claramente o ideário universalista que diversos autores (d'Adesky, 2001; Guimarães, 1999; Munanga, 1999) apontam como um dos fundamentos do nosso racismo, mas ainda falta aqui o uso explícito do discurso da mestiçagem, discurso bem mais eficiente, como veremos, no combate ao diferencialismo presente no modo bipolar.

\section{A mobilização do discurso da mestiçagem}

No Brasil, a questão da mestiçagem entra fortemente na pauta das discussões nacionais na segunda metade do século XIX. Não era sem preocupação que nossa elite intelectual, fortemente influenciada pelas idéias racistas importadas da Europa, discutia a nossa mistura racial e perguntava-se sobre as suas conseqüências para o destino da nacionalidade (Azevedo, 1987; Santos, 2002; Schwarcz, 1995).

Aos poucos, no entanto, começa a surgir um discurso que afirma a positividade da miscigenação. Essa ideologia da miscigenação se consolida no Brasil, como mostra Skidmore (1991), no início do século XX; nesse momento, segundo esse autor, a elite dominante argumentava confiantemente que o Brasil estava livre do racismo, porque estava formando uma única raça por intermédio da miscigenação. Para essa elite, a miscigenação possibilitaria o branqueamento do Brasil.

Com a tese do branqueamento, o caráter positivo da miscigenação passa a ser propagado com o uso dos mais variados argumentos. Num contexto ideológico como esse não nos deve surpreender o fato de que, na fala dos entre- 